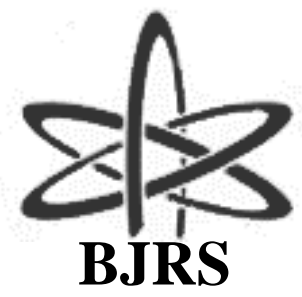

\author{
BRAZILIAN JOURNAL \\ $\mathrm{OF}$ \\ RADIATION SCIENCES \\ 09-01A (2021) 01-15
}

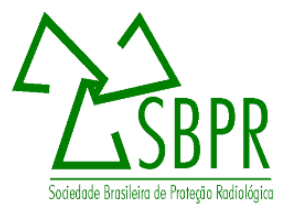

\title{
Optmization of exposure parameters in digital mammography (CR) using figure of merit
}

\author{
Morais I. S. ${ }^{1}$, Squair P.L. ${ }^{1}$, Souza, F.L ${ }^{1}$, Nogueira M.S. ${ }^{1}$ \\ Centro de Desenvolvimento da Tecnologia Nuclear (CDTN/CNEN) \\ Av. Presidente Antônio Carlos, 6.627 \\ Campus da UFMG - Pampulha 31270-901 \\ Belo Horizonte, MG, Brasil

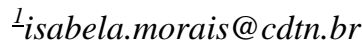

\begin{abstract}
A high diagnostic standard associated with the lowest radiation dose possible for the patient is the aim for a quality examination in mammography, this can be achieved through the Figure of Merit (FOM), which is a parameter used for optimization in digital mammography. The objective of this work was to determine the optimized radiographic technique ( $\mathrm{kV}$ and anode / filter combination) for the CR detection system (Computerized Radiography), using the parameter of the FOM, from the Contrast Noise Ratio (CNR) and the Average Glandular Dose (AGD), with two breast simulators (PMMA and CIRS) and perform a comparison between them. In order to calculate the AGD, the incident air kerma $\left(K_{a, i}\right)$ was measured and the $X$-ray beam characteristic factors were applied, according to the technical parameters used for each exposure performed in the simulators. In the optimization process, it was tested the Siemens Mammomat 3000 Nova Mammograph and the Kodak Direct View CR 850 System CR scanning system, using two breast simulators, PMMA and CIRS, with the following thicknesses: 2, 4.5 and $7 \mathrm{~cm}$. We calculated the FOM, for the optimized technique, with the values of AGD and CNR associated with each image, for the mammograph-CR set. Both simulators presented similar FOM for the tested conditions. The following $\mathrm{X}$-ray spectra were selected (anode/filter combination): $2 \mathrm{~cm}$ thick (Mo/Mo), 4.5 $\mathrm{cm}$ thick (W/Rh) and $7 \mathrm{~cm}$ thick (W/ Rh). The estimated doses referring to the optimized techniques found in this work respected the acceptable reference levels of the international protocols for quality control in mammography.
\end{abstract}

Keywords: Figure of merit, Mammography, Optimization. 


\section{INTRODUCTION}

According to the INCA [1] there are several types of breast cancer and these are the result of the disordered multiplication of cells, said abnormal, present in the breast. Breast cancer is the second most common type of cancer in women in Brazil and worldwide, accounting for about $29 \%$ of new cases each year in Brazil [1]. Men are also affected, but in these, the disease represents only $1 \%$ of the total cases. Mammography is a gold standard exam in the early detection of breast cancer by detecting subclinical lesions and also palpable masses, thus reducing the mortality rate and increasing the survival of patients $[2,3]$.

The mammography has a higher sensitivity for fat or lower density breasts, and $90 \%$ of malignant diseases [3]. In radiodiagnostic images, such as in mammography, it is important to obtain an image with high quality for the correct evaluation of the radiological findings and also taking into account the optimization rule of exposure (ALARA), which reduces the risk associated with the practice [4]. The optimization in digital mammography it is also related to a better quality of image (maximizing the contrast noise ratio) with the lowest possible dose to the patient [5].

The figure of merit (FOM) is a parameter used for optimization in digital mammography that relates the factors contrast noise ratio (CNR) and average glandular dose (AGD), seeking to obtain a maximum value of CNR, with a lowest possible AGD [6].

Therefore, the objective of this work is to determine the optimized radiographic technique $(\mathrm{kV}$ and anode/filter combination) for the CR detection system, using the FOM, from the CNR and the AGD, with two breast simulators (PMMA and CIRS) and to provide a posterior comparison between them.

\section{MATERIALS AND METHODS}

For the measurements it was used: The Siemens Mammomat 3000 Nova (CR) mammograph; 2, 4.5 and $7 \mathrm{~cm}$ thickness PMMA plates and 2 and $4.5 \mathrm{~cm}$ thicknesses of the CIRS phantoms. The phantoms images were obtained with different voltages $(26,28,30,32$ and $34 \mathrm{kV})$ and in different loads (mAs generated by the automatic control of exposure) in the anode / filter combinations 
available: the Mo / Mo, Mo / Rh and W / Rh. The images were saved in raw data mode, without processing.

To measure the incident air kerma $\left(\mathrm{K}_{\mathrm{a}, \mathrm{i}}\right)$, the Unfors solid-state detector was positioned at $4.5 \mathrm{~cm}$ high and $6 \mathrm{~cm}$ from the chest wall. It was performed corrections for the inverse of the square of the distance and the efficiency of the equipment was calculated. The average pixel value was measured from determined regions of interest (ROI) of the images, using the Image $\mathrm{J}$ software.

The CNR was calculated according to the equation 1 (Eq. 1), where the first ROI (M1) was positioned outside the aluminum region and the second ROI (M2) was located in the aluminum region, the $\mathrm{SD}$ is the average pixel counts of the $\mathrm{M} 1$ on the raw data image [7].

$$
C N R=\frac{M 1-M 2}{S D}
$$

The AGD was calculated according to the Equation 2 [10]. The $K_{a, i}$ is the incident air kerma, achieved with the Unfors solid-state detector. The conversions factor $\mathrm{g}, \mathrm{c}$ and s are respectively: the incident air kerma to mean glandular dose conversion factor, corrections for any difference in breast composition from $50 \%$ glandularity and the corrections for any difference from the original tabulation by Dance (1990), due to the use of a different X-ray spectrum [8,9]..

$$
A G D=K_{a, i}, c . g \cdot s
$$

The data analysis was performed using the following FOM equation (Eq.3) [10].

$$
F O M=\frac{C N R^{2}}{A G D}
$$

The same methodology was used for both simulators (PMMA and CIRS). The uncertainties of the calculations were performed and moreover, the Spearman correlation was applied in order to establish the relationship between FOM and its components (CNR, AGD and kV). The Spearman correlation makes an analysis of the result direction (Two possible analyzes whether both variables tend to increase or decrease together, or if one variable increase and another decreases) and 
resistance (relationship between the variables is stronger, as the absolute coefficient value is higher).

The monotonic relation between two variables, can be continuous or ordinal. In a monotonic relation, the variables tend to move in the same relative direction, but not necessarily at a constant rate. The coefficient varies between 1 and $-1, " 0 "$ means that there is no relation between the variables. The level of significance was set at 0.05 [11]. Furthermore, the Mann Whitney test was used to verify the equivalence between the simulators.

\section{RESULTS}

\subsection{Figure of Merit - FOM}

The Siemens Mammomat 3000 Nova presented the best acquisition parameters, for the Mo/Mo combination, for the phantom breasts (PMMA and CIRS) with the lowest thickness, the results showed an increase of $2 \mathrm{kV}$ for the PMMA simulator, as shown in Table 1. The PMMA phantoms with thickness greater than $2 \mathrm{~cm}$ presented corresponding techniques.

The $4.5 \mathrm{~cm}$ CIRS phantom presented an increase of $2 \mathrm{kV}$, in relation to its analogue in PMMA. The graphs for the tested breast phantoms with $2 \mathrm{~cm}$ and $4.5 \mathrm{~cm}$ showed similar behavior, taking into account the same simulator thickness (Fig. 1).

Table 1: Maximum values of FOM corresponding to Optimized techniques.

\begin{tabular}{ccc}
\hline \multicolumn{3}{c}{ FOM values for Optimized Techniques } \\
\hline \multirow{3}{*}{ Thickness $(\mathbf{c m})$} & Siemens Mammomat 3000 Nova & \\
$\mathbf{2}$ & PMMA $(\mathbf{c m})$ & CIRS (cm) \\
& $28 \mathrm{Mo} / \mathrm{Mo}$ & $(79.83)$ \\
$\mathbf{4 , 5}$ & $(73.13)$ & $32 \mathrm{~W} / \mathrm{Rh}$ \\
& $30 \mathrm{~W} / \mathrm{Rh}$ & $(15.86)$ \\
$\mathbf{7}$ & $(15.28)$ & $\mathrm{NT}$ \\
\end{tabular}




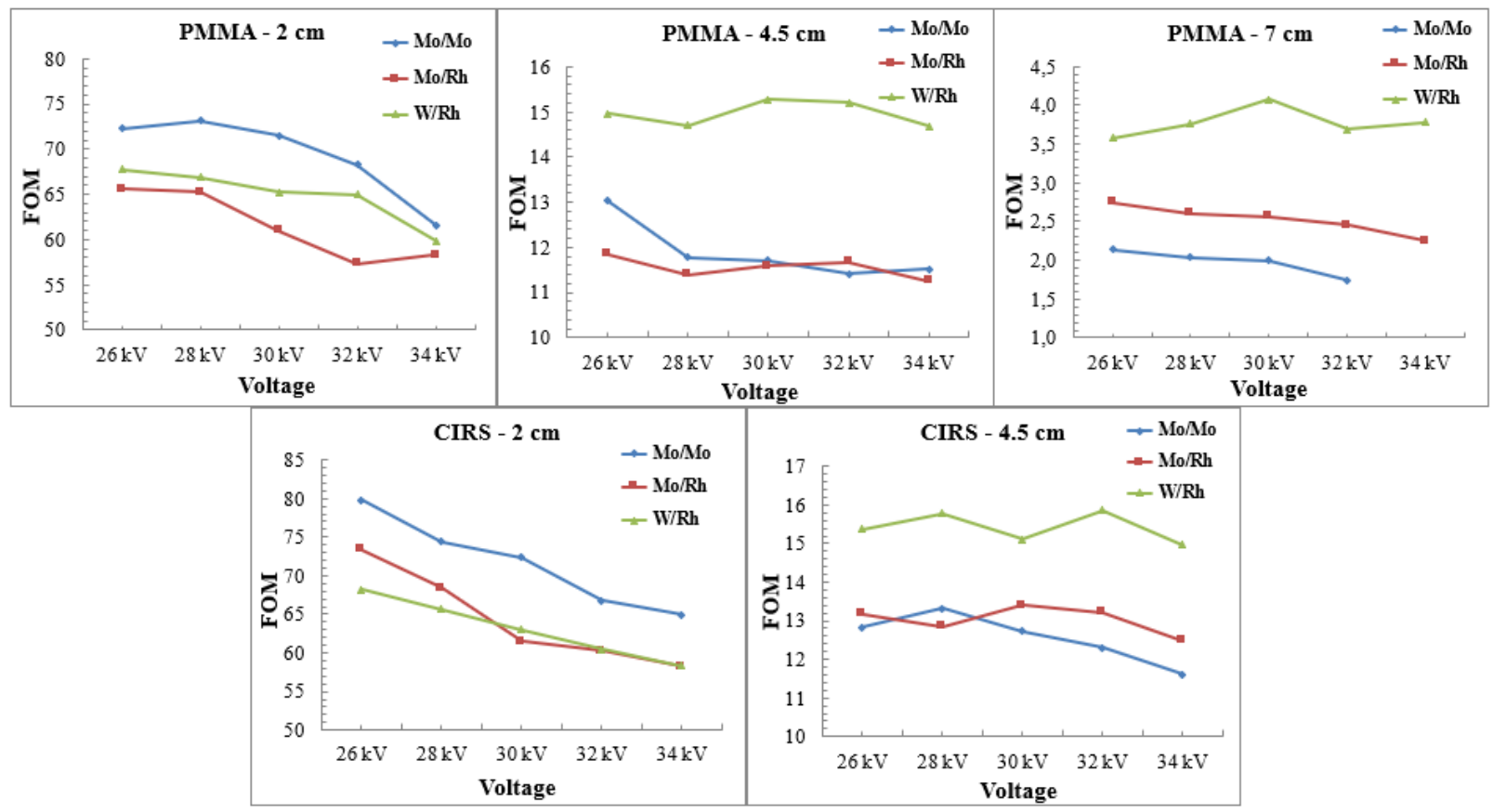

Figure 1: Relation between FOM $\left(C N R^{\wedge} 2 / A G D\right)$ and Voltage $(k V)$ for the Mammomat 3000 Nova mammograph, using the PMMA simulator and the CIRS simulator

\subsection{Average Glandular Dose - AGD}

For the lowest AGD values founded in this work, the set of technical parameters corresponding to the optimized techniques was not used; this is visualized in table 2. However, for the thicknesses of 4.5 and $7 \mathrm{~cm}$, the breast phantoms (PMMA and CIRS) presented the lowest AGD value. 
Table 2: Average Glandular Dose (AGD) for Optimized Techniques X lowest doses found on the mammograph Siemens Mammomat 3000 Nova

\begin{tabular}{|c|c|c|c|}
\hline \multirow[b]{2}{*}{ PMMA } & \multicolumn{3}{|c|}{ AGD } \\
\hline & $2 \mathrm{~cm}$ & $4.5 \mathrm{~cm}$ & $7 \mathrm{~cm}$ \\
\hline Optimized Techniques & $\begin{array}{c}0.46 \mathrm{mGy} \\
(28 \mathrm{kV}-\mathrm{MoMo})\end{array}$ & $\begin{array}{c}0.70 \mathrm{mGy} \\
(30 \mathrm{kV}-\mathrm{WRh})\end{array}$ & $\begin{array}{c}2.18 \mathrm{mGy} \\
(30 \mathrm{kV}-\mathrm{WRh})\end{array}$ \\
\hline $\begin{array}{c}\text { Techniques with Minor } \\
\text { Doses }\end{array}$ & $\begin{array}{c}0.22 \mathrm{mGy} \\
(34 \mathrm{kV}-\mathrm{WRh})\end{array}$ & $\begin{array}{c}0.53 \mathrm{mGy} \\
(34 \mathrm{kV}-W R \mathrm{Wh})\end{array}$ & $\begin{array}{c}1.34 \mathrm{mGy} \\
(34 \mathrm{kV}-\mathrm{WRh})\end{array}$ \\
\hline CIRS & $2 \mathrm{~cm}$ & $4,5 \mathrm{~cm}$ & $7 \mathrm{~cm}$ \\
\hline Optimized Techniques & $\begin{array}{c}0.48 \mathrm{mGy} \\
(26 \mathrm{kV}-\mathrm{MoMo})\end{array}$ & $\begin{array}{c}0.56 \mathrm{mGy} \\
(32 \mathrm{kV}-\mathrm{WRh})\end{array}$ & NT \\
\hline $\begin{array}{l}\text { Techniques with Minor } \\
\text { Doses }\end{array}$ & $\begin{array}{c}0.21 \mathrm{mGy} \\
(34 \mathrm{kV}-\mathrm{WRh})\end{array}$ & $\begin{array}{c}0.48 \mathrm{mGy} \\
(34 \mathrm{kV}-\mathrm{WRh})\end{array}$ & NT \\
\hline
\end{tabular}

NT: Not Tested

The results showed a decrease of dose, with the decrease of phantom thickness, which is expected, since it will require fewer amounts of x-ray photons to cross-smaller thicknesses. The doses for the optimized techniques were lower in the Mo / Mo spectrum for both simulators, as can be seen in Table 2 .

The AGD values, corresponding to the optimized techniques, founded in this study are far below what is considered desirable by radiation protocols, as can be seen in Table 3 . The maximum uncertainty of the AGD measurements for both simulators was $\pm 2.5 \%$

Table 3: Reference of AGD according to the Protocol for Quality Control of Mammographic Digital Systems [12] X Doses Corresponding to Optimized Techniques for both Simulators

\section{Reference AGD (PMMA)}

\begin{tabular}{cccc}
\hline & $\mathbf{2 ~ c m}$ & $\mathbf{4 . 5} \mathbf{~ c m}$ & $\mathbf{7 ~ c m ~}$ \\
\cline { 2 - 4 } $\begin{array}{c}\text { Ref. AGD Accepta- } \\
\text { ble }\end{array}$ & $<1 \mathrm{mGy}$ & $<2.5 \mathrm{mGy}$ & $<6.5 \mathrm{mGy}$ \\
$\begin{array}{c}\text { Ref. AGD Desirable } \\
\begin{array}{c}\text { Optimized Tech- } \\
\text { niques PMMA }\end{array}\end{array}$ & $0.6 \mathrm{mGy}$ & $<2 \mathrm{mGy}$ & $<5.1 \mathrm{mGy}$ \\
$\begin{array}{c}\text { Optimized Tech- } \\
\text { niques CIRS }\end{array}$ & $0.48 \mathrm{mGy}$ & $0.70 \mathrm{mGy}$ & $2.18 \mathrm{mGy}$ \\
\hline
\end{tabular}

NT: Not Tested 


\subsection{Contrast Noise Ratio - CNR}

The maximum CNR values were seen in the anode / filter combinations that produces fewer penetrating beams (less energy beams), which can be visualized in Figure 2. Moreover, under all the tested conditions, the CNR decreased with voltage increasing. This is due to the same reasons for using anode / filter combinations that produce lower energetic X-rays.

The $2 \mathrm{~cm}$ and $4.5 \mathrm{~cm}$ phantoms presented the same conditions for the maximum value of CNR, which were the following set of technical parameters: $26 \mathrm{kV}$ and Mo / Mo (Anode / Filter Combination). For the $2 \mathrm{~cm}$ PMMA phantom, the technique corresponding to the maximum value of CNR differed from the technique with respect to tension, for the CIRS simulator with same thickness this phenomenon was not observed.

For the thickness of $4.5 \mathrm{~cm}$, the optimized technique for both simulators diverged from the technique that corresponded to the maximum value of CNR. For the $7 \mathrm{~cm}$ phantom thickness there was divergence with the anode / filter combination. As observed in the AGD, these divergences may occur since that in the FOM calculations, the balance between the two quantities should be considered to achieve the optimized technique. The maximum uncertainty of the CNR measurements for the PMMA simulator was $\pm 1.20 \%$. For the CIRS simulator it was $\pm 1.13 \%$. 


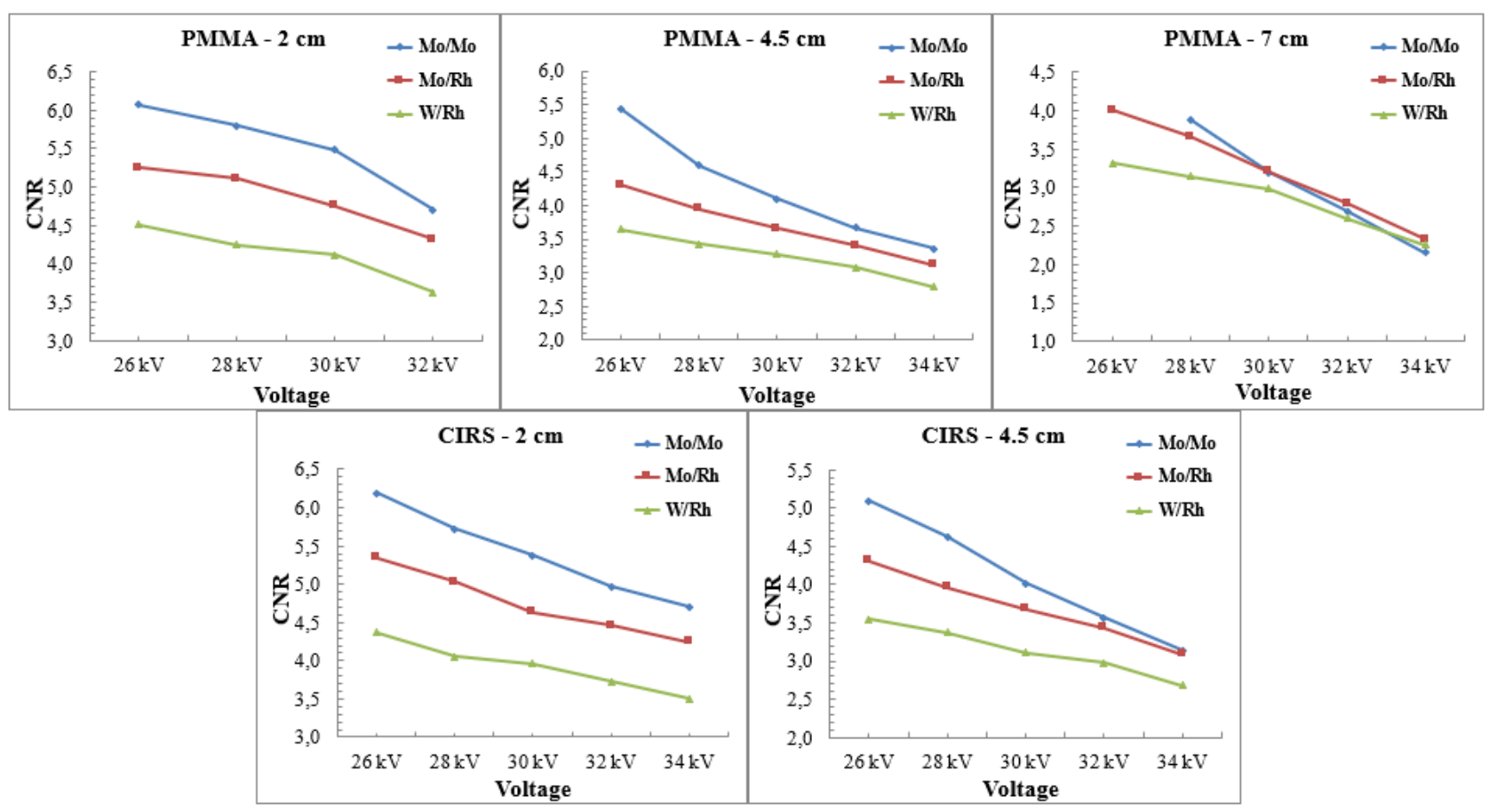

Figure 2: Relation between CNR and Voltage $(k V)$ for Siemens Mammomat 3000 Nova mammograph, using PMMA and CIRS phantoms.

\subsection{Statistical Analysis}

The statistical distribution of Spearman is shown in Tables 4, 5 and 6, where the FOM relations and their constituents were also established.

When the values are closer to 1 (Table 4, 5 and 6), the relation between voltage and FOM is stronger and linear. The signals (+or -) indicate that variables tend to increase or decrease together $(+)$, or if one variable tends to increase as the other decreases (-). In some cases, the level of significance was greater than 0.05 . 
Table 4: Spearman correlation (Voltage $\mathrm{x}$ FOM) for the two simulators tested (CIRS and PMMA) in all studied anode / filter combinations (Mo / Mo, Mo / Rh and W / Rh).

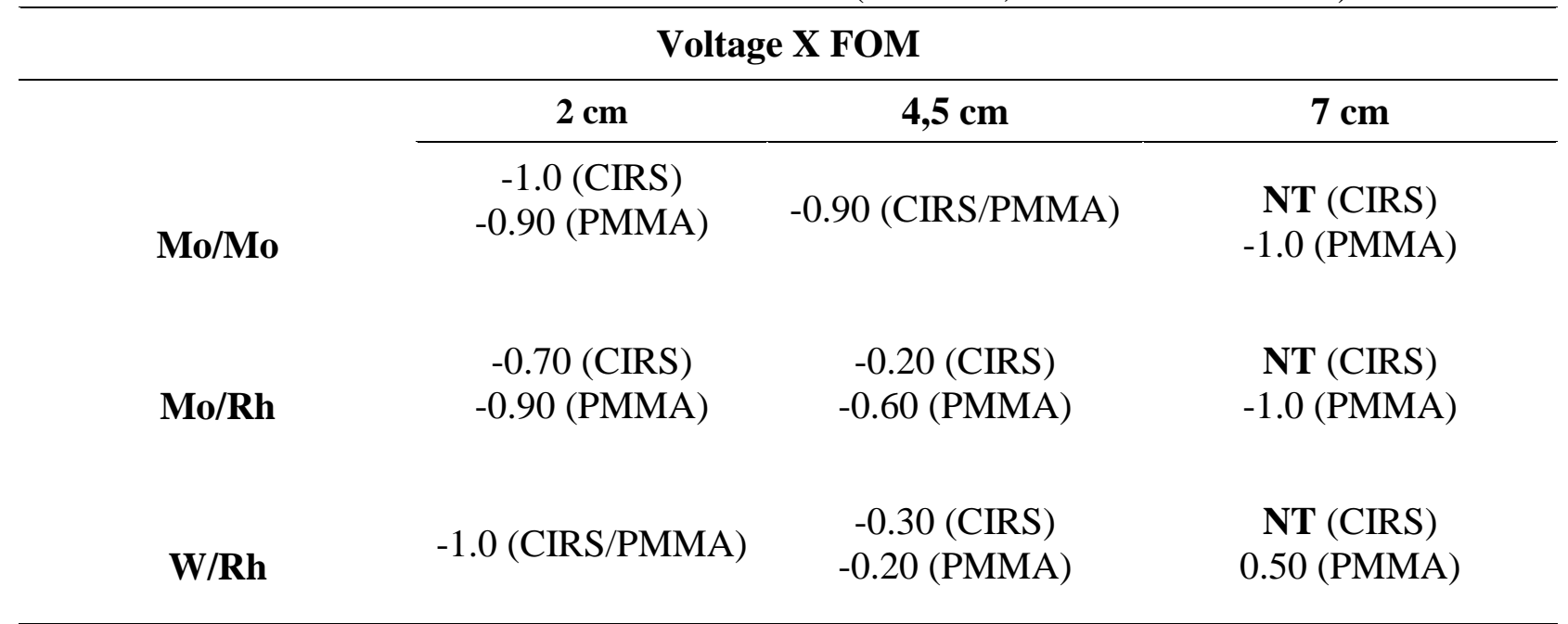

NT: Not Tested

Table 5: Spearman correlation (Contrast Noise Ratio x FOM) for the two simulators tested (CIRS and PMMA) in all studied anode / filter combinations (Mo / Mo, Mo / Rh and W / Rh).

\begin{tabular}{|c|c|c|c|}
\hline \multicolumn{4}{|c|}{ Contrast Noise Ratio X FOM } \\
\hline & $2 \mathrm{~cm}$ & $4.5 \mathrm{~cm}$ & $7 \mathrm{~cm}$ \\
\hline & $1.0(\mathrm{CIRS})$ & & NT (CIRS) \\
\hline Mo/Mo & 0.90 (PMMA) & 0.90 (CIRS/PMMA) & 1.0 (PMMA) \\
\hline & & $0.20(\mathrm{CIRS})$ & NT (CIRS) \\
\hline Mo/Rh & 0.90 (CIRS/PMMA) & 0.60 (PMMA) & 1.0 (PMMA) \\
\hline & & $0.30(\mathrm{CIRS})$ & NT (CIRS) \\
\hline $\mathbf{W} / \mathbf{R h}$ & 1.0 (CIRS/PMMA) & 0.20 (PMMA) & -0.50 (PMMA) \\
\hline
\end{tabular}

NT: Not Test

To define the equivalence between the FOMs of both tested phantoms, taking into account the conditions under which the experiments were performed, the Mann Whitney test was performed for significance of $\mathrm{p}<0.05$. The Mann Whitney test results are shown in Table 7 . Only for the $4.5 \mathrm{~cm}$ phantom thickness, with the anode/ filter combination of $\mathrm{Mo} / \mathrm{Rh}$, is equivalent in view of the Mann Whitney test with significance of $\mathrm{p}<0.05$. 
Table 6: Spearman Correlation (AGD x FOM) for the two simulators tested (CIRS and PMMA) in all studied anode / filter combinations (Mo / Mo, Mo / Rh and W / Rh).

\begin{tabular}{|c|c|c|c|}
\hline \multicolumn{4}{|c|}{ AGD X FOM } \\
\hline & $2 \mathrm{~cm}$ & $4,5 \mathrm{~cm}$ & $7 \mathrm{~cm}$ \\
\hline & $1.0(\mathrm{CIRS})$ & & NT (CIRS) \\
\hline Mo/Mo & 0.90 (PMMA) & 0.90 (CIRS/ PMMA) & 1.0 (PMMA) \\
\hline & $0.70(\mathrm{CIRS})$ & $0.20(\mathrm{CIRS})$ & NT (CIRS) \\
\hline Mo/Rh & 0.90 (PMMA) & 0.60 (PMMA) & 1.0 (PMMA) \\
\hline & $0.97(\mathrm{CIRS})$ & $0.30(\mathrm{CIRS})$ & NT (CIRS) \\
\hline W/Rh & 1.0 (PMMA) & 0.20 (PMMA) & -0.50 (PMMA) \\
\hline
\end{tabular}

NT: Not Tested

Table 7: Mann Whitney test result for simulators FOM equivalence

\begin{tabular}{|c|c|c|c|c|c|c|}
\hline & $\begin{array}{c}\mathrm{Mo} / \mathrm{Mo} \\
2 \mathrm{~cm} \\
\end{array}$ & $\begin{array}{c}\mathrm{Mo} / \mathrm{Rh} \\
2 \mathrm{~cm}\end{array}$ & $\begin{array}{c}\text { W/Rh } \\
2 \mathrm{~cm} \\
\end{array}$ & $\begin{array}{c}\mathrm{Mo} / \mathrm{Mo} \\
4.5 \mathrm{~cm} \\
\end{array}$ & $\begin{array}{l}\mathrm{Mo} / \mathrm{Rh} \\
4.5 \mathrm{~cm}\end{array}$ & $\begin{array}{l}\text { W/Rh } \\
4.5 \mathrm{~cm} \\
\end{array}$ \\
\hline $\begin{array}{c}\text { FOM } \\
\text { PMMA }\end{array}$ & $69.4 \pm 4.6$ & $61.4 \pm 4.0$ & $65.0 \pm 3.1$ & $12.0 \pm 0.7$ & $11.6 \pm 0.5$ & $15.0 \pm 0.3$ \\
\hline $\begin{array}{l}\text { FOM } \\
\text { CIRS }\end{array}$ & $71.6 \pm 5.9$ & $64.2 \pm 6.2$ & $63.0 \pm 4.1$ & $12.6 \pm 0.5$ & $12.8 \pm 0.4$ & $15.4 \pm 0.5$ \\
\hline $\begin{array}{c}\text { Dif. Per- } \\
\text { centual } \\
\text { Mann }\end{array}$ & $3.2 \%$ & $4.6 \%$ & $-3.1 \%$ & $5.0 \%$ & $10.3 \%$ & $2.8 \%$ \\
\hline $\begin{array}{c}\text { Whitney } \\
(p<0,05)\end{array}$ & $p>0.05$ & $p>0.05$ & $p>0.05$ & $p>0.05$ & $p<0.05$ & $p>0.05$ \\
\hline
\end{tabular}

\section{DISCUSSION}

For the tested equipment, the FOM did not presented a strong dependence on the anode / filter combination and the voltage, since the FOM values were close between the voltages and between the anode / filter combinations. Thus, it can adopt, besides the maximum FOM values, techniques with very close values. The results founded by Perez [10] in a mammographic equipment 
evaluation, using the $\mathrm{FOM}\left(\mathrm{CNR}^{\wedge} 2\right.$ / $\left.\mathrm{AGD}\right)$, presented a similarity with this statement, since the author reported that the FOM it is not dependent on the voltage, therefore can accepted in a wide voltage range. However, with respect to the anode / filter combination the author expressed that there was higher dependence.

The Siemens Mammomat 3000 NOVA used in its research has the following anode / filter combinations: Mo / Mo and Mo / Rh. In this research, for the same equipment, it was obtained a higher CNR for the anode / filter combination that produces the most penetrating X-ray beam (Mo / $\mathrm{Rh})$. Analogous to this study, the mammography used by Perez, presented higher dose for the Mo / Mo combination and also an increase of that dose value with the thickness. In all thicknesses tested by Perez, the FOM was larger for the anode / filter combination that produces the more energetic $\mathrm{x}$ ray beam, although the anode / filter combination was not the same in this study. This concept was applicable to $4.5 \mathrm{~cm}$ and $7 \mathrm{~cm}$ of thickness, independent of the simulator used. The FOM of the system used in this work (CR equipment) also presented decreasing with the thickness of the breast simulator.

For the evaluated device, the lowest values of DGM were not founded for the optimized techniques (lowest FOMs), but for others $\mathrm{kV}$ and $\mathrm{mAs}$ techniques. However, it is worth to remind that according to the ALARA principle, cited by Borg [13] and Hernandez [14], the dose required for the optimized the technique is what makes the exam feasible, so the divergence founded in voltage may not invalidate the FOM.

The maximum CNR values obtained in this research are shown in the anode / filter combinations that produce lower penetrating x-ray beams. However, this can be explained, since more penetrating x-ray beams decrease the contrast between the aluminum plate and the bottom of the image, interfering the maximum CNR values, as previously mentioned in Izdihar's work [16]. The CNR decreased with voltage increasing, also due to the use of anode / filter combinations that produce $\mathrm{x}$-rays that are more energetic.

Kanaga et al. [17] performed a study in three DR systems (Siemens Mammomat Novation DR, Hologic Lorad Selenia and General Electric (GE) Senographe) using the FOM, based on the contrast noise ratio and average glandular dose. The study showed that there was increase of the dose with the the breast thickness, demonstrating a directly proportional relation, as also been observed in this research. The $\mathrm{W} / \mathrm{Rh}$ and $\mathrm{Rh} / \mathrm{Rh}$ combinations tested by Kanaga showed lower 
AGD values when compared to Mo / Mo and Mo / Rh. Taking into account the situations tested in this work and making a comparison within the same conditions of tension and breast thickness, our results are similar to the ones observed by Kanaga et al., 2010.

In Kanaga et al. (2010) work, the parameters of the selected techniques for each device and all breast thickness were: W / Rh (DR Siemens); Rh / Rh (DR GE mammograph) and for the Hologic mammograph case, the Mo / Mo is more often than Mo / Rh, causing higher doses than the other devices.

The unit using W / Rh spectrum showed lower variation in CNR and the $\mathrm{Rh} / \mathrm{Rh}$ combination provided the best FOM values. Despite differences in Kanaga et al. (2010) research (types of mammograph, thickness, etc.) for this research; some results were similar, as already quoted above.

Merad et al., 2018 performed a work with full-field digital mammography (IMS Giotto and General Electric Senographe Essential), despite the essential differences in technology between Merad et al., 2018 work and this work, both surveys showed similar trends regarding the directly proportional behavior of AGD, characterized by increased AGD with breast thickness. In general, the FOM values presented by Merad et al., 2018 decreased with the increase of the simulator thickness, as in this work.

\section{CONCLUSION}

The FOM was the optimization parameter used in this study as a method of evaluating the performance of a CR equipment and an analog mammograph, in order to achieve the best relation between dose and image quality. It was possible to determine the highest values of FOM and the optimum tension for all the thicknesses of the phantoms. For the $2 \mathrm{~cm}$ phantoms thickness, the optimized technique was in the spectrum of the Mo / Mo anode / filter combination, independent of the phantom (PMMA or CIRS), but there was a small difference in the voltage between the simulators. For the thickness of $4.5 \mathrm{~cm}$, there was divergence in the voltage between the phantoms, for the same anode / W / Rh filter combination, also independent of the simulator. It was not possible to determine through FOM similarity between phantoms glandularities, considering the results of the Mann Whitney test for $\mathrm{p}<0.05$, since there was equivalence only for one FOM result. 
The FOM did not showed strong dependence with the voltage and anode / filter combination, and decreased with the thickness of the breast phantom.

The calculated doses referring to the optimized techniques found in this work respected the acceptable reference levels present in international radiation protocols.

\section{ACKNOWLEDGMENT}

The CDTN for encouraging research. CNPq (process $n^{\circ}$ 302014/2019-5), FAPEMIG - Scientific Initiation Scholarship (process $\mathrm{n}^{\circ}$ PPM-00643-16), funded this work. In addition, National Commission of Nuclear Energy (CNEN) for the Master's scholarship (process 01344000131/2019).

\section{REFERENCES}

[1] INCA - Instituto Nacional do Câncer José Alencar Gomes da Silva, Brasil. <http://www2.inca.gov.br/wps/wcm/connect/inca/portal/home>. Last accessed: 10 jun. 2019.

[2] BEZERRA, H.S.; MELO, T. F. V.; BARBOSA, J. V. ; FEITOSA, E. E. L. C. ; SOUZA, L. C. M. Avaliação do acesso em mamografias no Brasil e indicadores socioeconômicos: um estudo espacial. Rev. Gaúcha Enfermagem, v.39, p. 1-9, 2018.

[3] GIUlianO, A. E. Mama. In. WAY, L. W.; DOHERT, G. M. Cirurgia: Diagnóstico \& Tratamento, Rio de Janeiro: Guanabara Koogan, 2010.p 264-280.

[4] ICRP - International Commission on Radiological Protection. 1990 Recommendations of the International Commission on Radiological Protection. ICRP Publication 60, 1991. 21: p. 1201.

[5] WILliamS, M. B.; PRIYA, R.; MITALI, J. M.; SEIBERT, J. A.; KWAN, A.; LO, J. Y.; SAMEI, E.; RANGER, N. T.; FAJARDO, L. L.; MCGRUDER, A.; MCGRUDER, S. M.; MAIDMENT, A. D. A; YAFFE, M. J.; BLOOMQUIST, A.; MAWDSLEY, G. E. Optimization of exposure parameters in full field digital mammography. Med Phys. v. 35, p. 2414-23, 2008. 
[6] BORG, M.; BARD, I.; ROYLE, G.J. The use of figure-of-merit (FOM) for optimization in digital mammography: A literature review, Radiat. Prot. Dosim., v. 151, p. 81-88, 2012.

[7] NHSBSP - NHS Breast Screening Programme. Routine quality control tests for full field digital mammography systems - Fourth Edition (NHSBSP Equipment Report 1303). Sheffield: NHS Cancer Screening Programmes, 2013.

[8] DANCE, D.R.; SKINNER, C.L.; YOUNG, K.C; BECKETT, J. R.; KOTRE, C. J. Additional factors for the estimation of mean glandular breast dose using the UK mammography dosimetry protocol. Phys. Med. Biol. v. 45, p. 3225-3240, 2000.

[9] CEC - Commission of the European Communities. Directrices europeas para la garantía de calidad del cribado y diagnóstico del cáncer de mama. Cuarta edición (Luxembourg: CEC). 2006.

[10] PEREZ, A. M. M. M. ; POLETTI, M. E. ; TOMAL, A.; CORREIA, P. D.; PACIÊNCIA R. D.; SILVA, M. C. Estudo da Otimização em Sistemas de Mamografia Digital CR e DR. Rev. Bra. Fís. Méd., v. 11 , p.11-15, 2017.

[11] Suporte ao Minitab 18. Interpretar os principais resultados para Correlação, $<$ https://support.minitab.com/pt-br/minitab/18/help-and-how-to/statistics/basic statistics/howto/correlation/interpret-the-results/key-results/\#step-3-examine-the-monotonic-relationshipbetween-variables-spearman> Last accessed: 10 jun. 2019.

[12] MOTTA, V.T; FILHO, P.F.O. SPSS: Análise de Dados Biomédicos. Rio de Janeiro: MedbookEditora Científica Ltda., 2009. 334p. ISBN 9788599977347.

[13] CHEVALIER, M.; PENCO, P.M.; ECHEVARNE, J.J.M.; CABRERA, R.T. Protocolo para el Control de Calidad de los Sistemas Digitales Mamográficos. p.24, 2002.

[14] BORG, M.; KONSTANTINIDIS, A. Alternative Figures of Merit in Digital Mammography. Radiat. Prot. Dosim. v. 176, p. 388-399, 2017.

[15] HeRnÁNDEZ, J. M. C.; MIRAlleS, P. G.; PEÑAlVER, M. D. S.; MUÑOZ, N. L.; ESTEBAN, J. M. C.; BLANCA, J. I. V. Introducción de una figura de mérito para laevaluación conjunta de la calidad de imagen y la dosimetría en mamografía digital. Rev. Fis. Med. v. 19, p.103-9, 2018. 
[16] IZDIHAR, K. ; KANAGA, K. C.; KRISHNAPILLAI, V.; SULAIMAN, T., Determination of Tube Output $(\mathrm{kVp})$ and Exposure Mode for Breast Phantom of Various Thicknesses/Glandularity for Digital Mammography, Med. Jour. Mal. v. 22, p. 40-49, 2014.

[17] KANAGA, K. C. ; YAP, H. H.; LAILA, S. E.; SULAIMAN, T.; ZAHARAH, M.; SHANTINI M, A. A. A critical comparison of three full field digital mammography systems using figure of merit. Med. Jour. Mal. v. 65, p. 119-122, 2010.

[18] MERAD, A.; SAADI, S.; KHELASSI-TOUTAOUIL, N. Comparison of Two Full Field Digital Mammography Systems: Image Quality and Radiation Dose. AIP Conference Proceedings, p. 1-4, 2018. 